\title{
Impact of maternal childhood abuse history on child's attachment problems
}

Rie Mizuki ${ }^{1,2}$, Takeo Fujiwara ${ }^{1 *}$ and Makiko Okuyama ${ }^{2}$

*Correspondence: fujiwara-tk@ncchd.go.jp

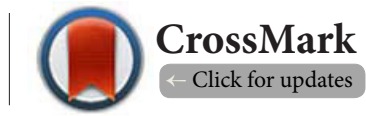

'Department of Social Medicine, National Research Institute for Child Health and Development, Tokyo, Japan.

${ }^{2}$ Department of Psychosocial Medicine, National Center for Child Health and Development, Tokyo, Japan.

\begin{abstract}
Background: The aim of this study was to investigate the independent impact of maternal childhood abuse history (MCAH), after controlling for maternal past, current parenting, and paternal past parenting, and maternal mental health $(\mathrm{MMH})$ on the attachment problems of children living in mother-child homes in Japan.

Methods: A self-administered questionnaire survey was conducted among mothers ( $\mathrm{N}=306)$ staying in 83 mother-child homes in Japan to assess mothers' and fathers' maltreatment toward their children before moving into the homes, mothers' current maltreatment, $\mathrm{MMH}$ and MCAH in relation to their children's $(\mathrm{N}=310)$ attachment problems.

Results: MCAHs were significantly and independently associated with children's attachment problems after controlling for maternal past, current maltreatment, and paternal past maltreatment. Among covariates, $\mathrm{MMH}$, especially dissociation, was independently significantly associated with children's attachment problems.

Conclusions: The finding that MCAH has a significant impact on children's attachment problems, independent of parental maltreatment, suggests inter-generational continuity of child maltreatment.
\end{abstract}

Keywords: Child abuse, inter-generational continuity, attachment, mental health, dissociation

\section{Introduction}

The significance of the attachment relationship between an infant and caregiver has been shown by numerous empirical findings [1-5]. This emphasizes the importance of the infant caregiver relationship early in life, providing the basis for healthy development. Thus, parenting quality is important for attachment security [6], and child maltreatment was associated with attachment insecurity [7]. Similar to child maltreatment, poor parenting practice, or less severe form of neglect, have attracted research attention. They are characterized by less sensitive and inconsistent parenting [8], permissive parenting [9], poor mother-child interactions [10], contradictory signaling, role confusion, and fearful or withdrawal behaviors [11]. These parenting practices do not necessarily reflect active engagement in violence, verbal condemnation, or exploitation on the part of the parent, described as child abuse usually, but they feature passive engagement in rejection or lack of availability. While some features of poor parenting may seem more subtle than severe abuse, they are also so harmful that mothers who use such parenting methods are able to predict the poor attachment development of their children.

Given the critical role of parenting in the development of attachment relationships, intergenerational continuity of parenting practices has been suggested as an explanation for the choice of parenting style, that is, mothers with childhood abuse history might be associated with insecure attachment of children, including less severe form of child maltreatment. Many mothers who abuse their children have been abused in childhood by their parents [12-14]. Such research findings suggest a cycle of childcare and abuse in which a mother with history of being abused as a child is more likely to abuse her child. In addition to parenting practices, attachment strategies (i.e., secure/insecure attachment type) can be also transmitted from grandmother to mother [15]. Thus, it is possible that childhood abuse history may be associated with poor parenting, or less severe form of child maltreatment, but also 
Mizuki et al. Paediatrics and Health 2015,

http://www.hoajonline.com/journals/pdf/2052-935X-3-3.pdf

doi: $10.7243 / 2052-935 X-3-3$

through attachment insecurity; however, few studies have investigated this topic.

When a woman has a history of being abused as a child, such traumatic experiences may have deteriorated her mental health for a long time and may compromise her parenting ability. Mothers' mental health has been recognized as a predictor of children's developmental trajectories. For example, maternal depression is associated with behavior problems in children $[16,17]$ and attachment insecurity $[18,19]$. Since mothers' mental health could be related to children's attachment through disparate parenting, which is not necessarily abusive, but is less than optimal in terms of responsiveness, sensitivity, and/or consistency, the assessment of mothers' mental health and the measurement of its effect on children's development of attachment style is inevitable.

The mother is not the only person influencing the development of the child's attachment style; other significant adults, including the father, also affect the child's attachment style [20]. The quality of fathers' interactions with children is associated with children's attachment [21]. The quality of fathers' interactions with their children during problem-solving tasks at 24 months predicted the children's secure attachment at the age of 10, whereas the quality of mothers' interactions did not [22]. Despite this view of parenting unique to fathers, few studies have examined how paternal and maternal parenting independently impacts the development of a child's attachment style.

Studies on maltreatment often aggregate its subtypes and employ the dichotomy of its presence or absence. However, it is not clear how each subtype of maltreatment (i.e., physical, psychological, or sexual abuse, and neglect) influences a child's attachment style. For instance, severe physical violence may be related to more negative outcomes in child-mother relationships than the mother's hurtful words to the child. Thus, it is necessary to examine what type of maltreatment is associated with attachment problems.

In Japan, mothers who suffer from domestic violence, who want to separate from their husbands or partners because of their partner's abuse of their children, or who have financial problems can stay at mother-child homes with their children, similar to shelters in the U.S. Through such homes, we can assess the impact of paternal and maternal parenting (including child maltreatment subtypes) before moving into a mother-child home, current maternal parenting, mental health, and childhood abuse history on the child's attachment problems. Thus, the purpose of this study is to investigate the impacts of paternal and maternal parenting (including child maltreatment subtypes) before moving into a mother-child home, current maternal parenting, mental health, and childhood abuse history on the attachment problems in children living in mother-child homes in Japan.

\section{Methods \\ Participants}

Mothers living in mother-child homes, where mothers with children can live and receive a variety of social and welfare assistance (e.g., occupational training, residential assistance, and psychological services), were recruited through a study announcement at all mother-child homes in Japan $(N=83)$. A questionnaire packet was sent to 421 mothers who had agreed to participate. Three hundred forty maternal cases (80.1\%) and 306 child cases (ages 6 years and younger) with valid responses were collected. The mothers who agreed to participate in the study completed questionnaires on their parenting practices as well as on the behavior of each of their children. One questionnaire was filled out for each child; for example, a mother with two children completed two child behavior questionnaires in total. After completion of the survey, each participant sent the questionnaires back to the researcher via mail. The child behavior questionnaire was labeled with mother's ID number for statistical analysis. We don't have data on non-respondents, thus we cannot compare the characteristics of respondents and non-respondents.

The study was approved by the Institutional Review Board at the National Research Institute for Child Health and Development. For anonymity, the participants were instructed to respond the questionnaires alone and a consent form was not required.

\section{Measures}

\section{Maternal childhood abuse history (MCAH)}

An MCAH questionnaire was developed based on the Childhood Trauma Questionnaire [23]. It was translated into Japanese and modified to include only seven items in order to minimize the burden on the participants. The seven items asked about mothers' victimization of violence, neglect, verbal abuse, and sexual abuse during their childhood. Each question was answered on 4-point Likert scale, where 1=not at all, $2=$ rarely, $3=$ sometimes and $4=$ frequently. The total score was calculated by summing all the responses. The scale was used in the analysis of previous literature [24-29].

\section{Maternal mental health (MMH)}

The questionnaire to assess mother's mental health was developed from the Diagnostic Statistical Manual of Mental Disorders-IV [30] and employed in previous studies [e.g., 31]. The questionnaire consisted of three subscales: depressive, dissociative, and traumatic symptomatology. The dissociative subscale was composed of 10 items asking about mothers' experiences characteristic to dissociation while they care for their children. Mothers responded according to the 4-point Likert scale described above (in the section for MCAH). The scores of those 10 items were summed to calculate a total dissociative score. Depressive and traumatic subscales were comprised of 11 and eight items, respectively. The scale was used in the analysis of previous literature [24-29].

\section{Child maltreatment}

Mothers were asked to report their children's maltreatment 
and poor parenting at two points in time: before and after moving into the mother-child home. There were five items asking about parenting practices, and these items were classified into three maltreatment subtypes: physical abuse, neglect, and psychological abuse, with items addressing playing with the child (reverse for neglect) and praising the child (reverse for verbal abuse) as well. Since few mothers commit sexual abuse, sexual abuse was not included in this study. For physical abuse, mothers were asked how frequently they had practiced/currently practice beating and kicking their children. For psychological abuse, mothers were questioned how often they had practiced/currently practice saying hurtful words to their children. Neglect was assessed by asking mothers about their current and past experiences of failing to provide the necessary care for the child's survival (e.g., meals and clothes). The questionnaire also asked how often mothers were/are engaged in playing and talking with their children, as well as how often they had praised/ currently praise their children (reverse coded). For father's maltreatment, mothers were asked to report physical abuse, psychological abuse, neglect and sexual abuse committed by their husbands or unmarried, cohabited partners before moving into the mother-child home. The responses were reported on a 4-point Likert scale, as described above. The score for neglect was calculated by averaging responses to the two questions pertaining to neglect. The questionnaire was developed from the Japanese version of Maltreatment [32]. In an effort to minimize the burden on the respondents, the question items were modified from the Center's original 17 questions to only five items. The scale was used in the analysis of previous literature $[25,26,29]$.

\section{Attachment problems}

The Checklist for Maltreated Young Children [CMYC; 33] was used to measure behavioral problems which are particularly characteristic of maltreated children under the age of 7. There are two versions of the CMYC; one is for 6-24 month-old children, and the other is for 2-6 year-old children. Both versions of the CMYC have been standardized and validated for identifying children who have been exposed to maltreatment. Among other problems, the CMYC assesses problems with the development of attachment relationships. The attachment subscale has 16 items asking if the child shows certain behaviors (e.g., your child freezes when experiencing fear, pain, or an unpleasant feeling), and mothers respond on a 4-point Likert scale, where $1=$ not at all, $2=$ sometimes does, $3=$ does and $4=$ frequently does. The scores were summed and converted to T-scores such that the scores from the two versions could be integrated.

\section{Limitation of measurements}

$\mathrm{MCAH}, \mathrm{MMH}$, and child maltreatment were assessed retrospectively and by self-report, these variables contain recall bias and might have been influenced by mental health problems.
In other words, a mother with MCAH might not be able to recall her MCAH or child maltreatment due to dissociation while responding. Moreover, feeling of guilt or shame on poor parenting might have led to reporting bias when mothers respond to the child maltreatment assessment. Regarding the father's maltreatment before moving into the home, the assessment relied on the mother's report, and therefore, this measurement may also be biased because of relational issues between the parents. In addition, this study did not use standard assessment tools, such as the Childhood Trauma Questionnaire [23] for MCAH, Beck Depression Inventory for $\mathrm{MMH}$, Atypical Maternal Behavior Instrument for Assessment and Classification [34] for parenting practices, and the Strange Situation coding procedures $[35,36]$ for the child's attachment problems, although some of these assessment tools were referenced during the development of the questionnaires. Since it is extremely difficult to use lengthy standard scales as well as experimental settings for women and their children living in mother-child homes, this study prioritized convenience for the participants by adhering to a self-report questionnaire and minimizing its volume.

\section{Covariates}

Potential confounders were assessed in the questionnaire. For each mother, her age, current marital status, current working status, length of stay in the mother-child home, and professional support (i.e., medical or legal support, including psychotherapy) were assessed. For each child, the age, sex, birth order, biological status, medical treatment, and other welfare/educational support were included. Details of the items used to assess these covariates are shown in Table 1.

\section{Analysis}

First, Spearman's correlation coefficients were calculated to observe associations among maltreatments, since maltreatment variables are not normally distributed. Second, a bivariate generalized estimating equation (GEE) was used, which adjusts for the clustering of attachment problems among siblings, to see the crude association between each maltreatment and the child's attachment problems. Third, in order to see the independent effects of each maltreatment, multivariate GEEs were performed with adjustment for covariates. Starting with the mother's current maltreatment, the mother's maltreatment before moving into the home, father's maltreatment before moving into the home, $\mathrm{MMH}$, and $\mathrm{MCAH}$ were added to the analysis as the model progressed from Model 1 to Model 5. Fourth, the effects of subtypes of maltreatment and subtypes of mental health symptoms were examined by two bivariate GEEs with and without adjustment and one multivariate GEE including all the predictors simultaneously with adjustment. To avoid complications in the interpretation of the regression coefficients, maltreatment, $\mathrm{MMH}$ and MCAH were converted to a score on the scale from 0 to 10 . A $p<0.05$ was considered significant. All analyses were performed with Stata IC 11.0. 
Mizuki et al. Paediatrics and Health 2015,

http://www.hoajonline.com/journals/pdf/2052-935X-3-3.pdf

doi: $10.7243 / 2052-935 X-3-3$

Table 1. Characteristics of sample.

\begin{tabular}{llll}
\hline & & $\begin{array}{l}\text { Mean (SD) } \\
\text { or N (\%) }\end{array}$ & Range \\
\hline Child characteristics $(\mathbf{n = 3 1 0})$ & & \\
\hline Child's age (years) & -- & $3.9(1.8)$ & $0.08-6.90$ \\
\hline Sex & Male & $163(52.6)$ & -- \\
& Female & $147(47.4)$ & -- \\
\hline Birth order & $1^{\text {st }}$ & $147(52.69)$ & -- \\
& $2^{\text {nd }}$ & $82(29.39)$ & -- \\
& $3^{\text {rd }}$ & $42(15.05)$ & -- \\
\hline Biological child & $4^{\text {th }}$ & $5(1.79)$ & -- \\
& $5^{\text {th }}$ & $3(1.08)$ & -- \\
\hline Receiving medical & Yes & $308(99.68)$ & -- \\
care & No & $1(0.32)$ & -- \\
\hline $\begin{array}{l}\text { Receiving other } \\
\text { professional support }\end{array}$ & Yes & $260(83.87)$ & -- \\
& No & $50(16.13)$ & -- \\
\hline
\end{tabular}

Family characteristics $(n=306)$

\begin{tabular}{|c|c|c|c|}
\hline Mother's age (years) & -- & $32.6(5.7)$ & $19-52$ \\
\hline $\begin{array}{l}\text { Husband or Partner's } \\
\text { age (years) }\end{array}$ & -- & $36.69(8.96)$ & $21-70$ \\
\hline \multirow[t]{3}{*}{ Marital status } & Married & $58(19.08)$ & -- \\
\hline & Cohab., Unmarried & $78(15.79)$ & -- \\
\hline & Divorced & $198(65.13)$ & -- \\
\hline \multirow{4}{*}{$\begin{array}{l}\text { Maternal working } \\
\text { status }\end{array}$} & Vocational training & $11(3.59)$ & -- \\
\hline & Working part-time & $172(56.21)$ & -- \\
\hline & Working full-time & $73(23.86)$ & -- \\
\hline & Unemployed & $50(16.34)$ & -- \\
\hline $\begin{array}{l}\text { Length of stay in } \\
\text { mother-child homes } \\
\text { (years) }\end{array}$ & -- & $1.477(1.27)$ & $0-6.08$ \\
\hline \multirow{2}{*}{$\begin{array}{l}\text { Receiving } \\
\text { professional support }\end{array}$} & Yes & $108(36.12)$ & -- \\
\hline & No & $191(63.88)$ & -- \\
\hline \multirow{3}{*}{$\begin{array}{l}\text { Reason for staying } \\
\text { at mother-child } \\
\text { homes(Multiple } \\
\text { Responses) }\end{array}$} & Domestic violence & $176(57.52)$ & -- \\
\hline & $\begin{array}{l}\text { Abuse to child by } \\
\text { male partner }\end{array}$ & $56(18.3)$ & -- \\
\hline & Other & $157(51.31)$ & -- \\
\hline
\end{tabular}

\section{Results}

The characteristics of the sample are shown in Table 1. The mean age of the children was 3.9 years $(S D=1.8)$. Out of 310 children, 163 (52.6\%) were male. More than half (52.7\%) of the children were the first-born child. All of them, except for one child, were the biological children of their mothers. Two hundred sixty (83.9\%) children were receiving some medical care, and 59 (19\%) children were receiving other professional support, including psychotherapy and involvement with the Child Protective Services. The mother's mean age was 32.6 years $(S D=5.7)$, and the father's (including unmarried, cohabited partners) mean age was 36.7 years ( $S D=9.0)$. While $65.1 \%$ of mothers had divorced their partners at the time of the survey, $58(19.1 \%)$ mothers remained married. Almost $80 \%$ of mothers were working either full-time or part-time. More than half of the mothers reported that domestic violence was the reason for moving into the mother-child home, and $18.3 \%$ reported that their partners' abuse toward the child was the reason. The mean length of stay at the home was 1.5 years $(S D=1.3)$.

Table 2 describes the Spearman correlations among the total scores of the mother's current maltreatment, mother's maltreatment before moving into the home, father's maltreatment before moving into the home, $\mathrm{MMH}$, and $\mathrm{MCAH}$. Significant correlations $(r=0.14$ to $0.30, p<0.05$ ) were found in all variable combinations except for the correlation between the mother's current maltreatment and father's maltreatment before moving into the home.

The results of bivariate and multivariate linear regression of maltreatments, $\mathrm{MMH}$, and MCAH for child attachment problems are shown in Table 3. In the adjusted bivariate model (Model 1), mother's current maltreatment, mother's maltreatment before moving into the home, father's maltreatment before moving into the home, MMH, and MCAH were significantly associated with attachment problems in the child (coefficients: 1.89, 1.99, $1.72,3.1$ and 2.15 , respectively; $p<0.05$ ). Table 3 also shows the results of the multivariate linear regressions assessing the independent effects of mother's current maltreatment and maltreatment before moving into the home, father's maltreatment before moving into the home, $\mathrm{MMH}$, and $\mathrm{MCAH}$ on child attachment problems. In Model 2, the total scores of the mother's current maltreatment and maltreatment before moving into the home were included and had coefficients of 1.5 and 1.44 , respectively, both of which were statistically significant, a result that was slightly attenuated from Model 1. In Model 3, adding the total score of the father's maltreatment before moving into the home to Model 2, the father's maltreatment showed a significant coefficient (1.24), but the mother's current maltreatment became non significant (coefficient: 1.42). In Model 4, where the MMH was added to the previous model, the MMH showed a higher coefficient (2.34), but the father's maltreatment became non significant (coefficient: 1.05). In the final model (Model 5), adding the $\mathrm{MCAH}$, only MMH and MCAH were independently associated with child attachment problems (coefficients: 2.07 and 1.41, respectively).

Table 4 presents the coefficients of crude and adjusted bivariate regressions and a multivariate regression for maltreatment subtypes, MMH subtypes, and the MCAH on child attachment problems. In the bivariate adjusted model, $\mathrm{MMH}$ symptoms of dissociation showed the highest coefficient $(3.41, p<0.05)$, followed by the mother's physical abuse before moving into the home (coefficient: $2.27, p<0.05$ ) and 
Mizuki et al. Paediatrics and Health 2015,

http://www.hoajonline.com/journals/pdf/2052-935X-3-3.pdf

doi: 10.7243/2052-935X-3-3

Table 2. Spearman's correlation matrix of predictor variables.

\begin{tabular}{llllll}
\hline & $\begin{array}{l}\text { Mother's current } \\
\text { maltreatment }\end{array}$ & $\begin{array}{l}\text { Mother's past } \\
\text { maltreatment }\end{array}$ & $\begin{array}{l}\text { Father's past } \\
\text { maltreatment }\end{array}$ & MMH & MCAH \\
\hline Mother's current maltreatment & 1.00 & -- & -- & -- & -- \\
Mother's past maltreatment & $0.15^{\star}$ & 1.00 & -- & -- & -- \\
Father's past maltreatment & 0.12 & $0.20^{\star}$ & 1.00 & -- & -- \\
MMH & $0.24^{\star}$ & $0.23^{\star}$ & $0.19^{\star}$ & 1.00 & -- \\
MCAH & $0.16^{*}$ & $0.22^{\star}$ & $0.14^{*}$ & $0.30^{*}$ & 1.00 \\
\hline
\end{tabular}

Note: All predictor variables ranged from $0-10$.

${ }^{*} p<0.05$

Table 3. Regression coefficients of parental maltreatment, MMH, MCAH for child attachment problem.

\begin{tabular}{|c|c|c|c|c|c|c|c|}
\hline Variable & $\mathrm{M}(\mathrm{SD})$ & Crude & $\begin{array}{l}\text { Model } 1 \text { (bivariate, } \\
\text { adjusted for covariates) }\end{array}$ & Model2a & Model3 $^{\mathrm{a}}$ & Model4a & Model5a \\
\hline Mother's current maltreatment total & $1.49(1.39)$ & $1.32^{*}$ & $1.89^{*}$ & $1.50^{*}$ & 1.42 & 0.63 & 0.45 \\
\hline Mother's past maltreatment total & $1.62(1.68)$ & $2.06^{*}$ & $1.99^{*}$ & $1.44^{\star}$ & $1.19^{*}$ & $1.17^{*}$ & 1.07 \\
\hline Father's past maltreatment total & $1.40(1.74)$ & $1.26^{*}$ & $1.72^{\star}$ & -- & $1.24^{*}$ & 1.05 & 0.91 \\
\hline MMH total & $3.22(1.97)$ & $3.08^{\star}$ & $3.10^{*}$ & -- & -- & $2.34^{*}$ & $2.07^{\star}$ \\
\hline MCAH history & $1.59(1.86)$ & $2.26^{*}$ & $2.15^{\star}$ & -- & -- & -- & $1.41^{\star}$ \\
\hline
\end{tabular}

Note: All predictor variables ranged from 0-10. Attachment problem was in T-score.

aAdjusted for mother's age, child's age, child's sex, child's birth order, medical treatment, and welfare/educational support.

${ }^{*} p<0.05$

the MCAH (coefficient: 2.15, $p<0.05$ ). Then, 21 subtypes in all categories and the total score for the MCAH were included in the multivariate model. In this analysis, we found that only dissociation of MMH subtypes and MCAH were significantly associated with attachment problems, although the results were attenuated from the bivariate adjusted model (coefficients: 1.66 and 1.70 , respectively).

\section{Discussion}

MCAH and MMH were shown to be independently significantly associated with attachment problems in children, while child maltreatment was not found to be associated with attachment problem after adjusting for MCAH and MMH. In the bivariate analysis of subtypes of $\mathrm{MMH}$ and child maltreatment, dissociative symptoms and the mother's physical abuse to her child before moving into the mother-child home were shown to have a stronger impact on child attachment problems than other subtypes. However, in multivariate analysis including all the subtypes and MCAH, only dissociative symptoms and MCAH remained significantly associated with the child's attachment problems, with the coefficients attenuated from the bivariate analysis, suggesting that maternal child maltreatment mediated the association between MCAH or MMH and child attachment problems.

To the best of our knowledge, the present study is the first to show a link between MCAH and child attachment problems, independent from maternal child maltreatment and $\mathrm{MMH}$. A possible explanation for the link between MCAH and attachment problems in children, not occurring through child maltreatment or $\mathrm{MMH}$, is suboptimal poor parenting (i.e., parenting behaviors), which is not measurable as child maltreatment, but may appear during daily parenting, including lack of responsivity to the child or poor affective communication [37].

Besides MCAH, MMH was also independently associated with the child's attachment problems. The present study is consistent with previous studies indicating the impact of $\mathrm{MMH}$ on child's attachment security [38]. Although each subtype of MMH (dissociative, depressive, and traumatic symptoms) had a significant impact on child attachment problems in bivariate analyses, only mother's dissociative symptoms, but neither depressive nor traumatic symptoms, predicted attachment problems in multivariate analysis. Dissociation usually involves sudden onset of freezing and losing track of time, which can interfere significantly with mother-child communication and results in poor responsivity and inconsistent parenting. Recent research has suggested that dissociation during parent-child communication is strongly related to attachment insecurity $[39,40]$. Non significant associations between depressive and traumatic symptoms on child attachment problems may be attributed to consistent parenting despite these symptoms.

Child maltreatment was not significantly associated with child attachment problems in multivariate analysis. This result appears to contradict the literature, in which the link between poor parenting and attachment insecurity has been repeatedly presented [e.g., 41]. However, the majority of the 
Mizuki et al. Paediatrics and Health 2015,

http://www.hoajonline.com/journals/pdf/2052-935X-3-3.pdf

doi: $10.7243 / 2052-935 X-3-3$

Table 4. Regression coefficients of subtypes of parental maltreatment, MMH and total MCAH on child attachment problem.

\begin{tabular}{|c|c|c|c|c|}
\hline Variable & M(SD) & Bivariate & $\begin{array}{l}\text { Bivariate } \\
\text { adjusted }^{\mathrm{a}}\end{array}$ & $\begin{array}{l}\text { Multivariate } \\
\text { adjusted }^{\text {a }}\end{array}$ \\
\hline \multicolumn{5}{|l|}{ Mother's current maltreatment } \\
\hline Physically abuse child & $2.31(2.50)$ & 0.60 & $0.87^{\star}$ & -0.06 \\
\hline Neglect child's needs & $0.61(1.66)$ & 0.11 & 0.57 & -0.15 \\
\hline Verbally abuse child & $2.00(2.38)$ & $1.16^{*}$ & $1.73^{*}$ & 0.76 \\
\hline Play with child (reverse) & $1.34(2.11)$ & 0.12 & 0.04 & -0.06 \\
\hline Praise child (reverse) & $1.16(2.05)$ & 0.20 & 0.09 & -0.85 \\
\hline \multicolumn{5}{|l|}{ Mother's past maltreatment } \\
\hline Physically abused child & $1.41(2.35)$ & $1.49^{*}$ & $2.27^{\star}$ & 0.66 \\
\hline Neglected child's needs & $0.70(2.01)$ & 0.93 & 0.99 & 0.74 \\
\hline Verbally abused child & $1.47(2.47)$ & $1.24^{*}$ & $1.70^{*}$ & 0.77 \\
\hline Played with child (reverse) & $2.41(3.36)$ & $0.69^{*}$ & 0.53 & 0.31 \\
\hline Praised child (reverse) & $2.15(3.16)$ & 0.40 & 0.12 & -0.24 \\
\hline \multicolumn{5}{|l|}{ Father's past maltreatment } \\
\hline Hit child & $1.57(2.75)$ & 0.46 & $0.73^{\star}$ & -0.79 \\
\hline Severely hit child to injury & $0.56(1.8)$ & $1.25^{\star}$ & $1.53^{*}$ & 1.32 \\
\hline Deprived child of food & $0.40(1.62)$ & 0.53 & $0.73^{*}$ & -0.88 \\
\hline Verbally abused child & $2.07(3.36)$ & $0.67^{*}$ & $0.87^{\star}$ & 0.57 \\
\hline Neglected child's behavior & $2.51(3.59)$ & $0.50^{*}$ & $0.71^{*}$ & 0.08 \\
\hline Coerced child into hitting mother & $0.37(1.59)$ & 0.76 & 0.91 & -0.31 \\
\hline Physically abused mother in front of child & $3.36(4.12)$ & 0.36 & 0.43 & 0.07 \\
\hline Coerced child into sexual contact & $0.04(0.35)$ & 0.28 & -0.23 & -0.93 \\
\hline \multicolumn{5}{|l|}{ MMH } \\
\hline Dissociation & $2.46(1.77)$ & $3.35^{*}$ & $3.41^{*}$ & $1.66^{*}$ \\
\hline Depression & $3.89(2.47)$ & $1.95^{\star}$ & $1.90^{*}$ & 0.83 \\
\hline Trauma & $3.29(2.44)$ & $1.80^{*}$ & $1.84^{\star}$ & 0.24 \\
\hline MCAH & $1.59(1.86)$ & $2.26^{*}$ & $2.15^{\star}$ & $1.70^{\star}$ \\
\hline
\end{tabular}

Note: All predictor variables ranged from 0-10. Attachment problem was in T-score.

aAdjusted for mother's age, child's age, child's sex, child's birth order, medical treatment, and welfare/educational support.

${ }^{*} p<0.05$

previous studies observed a crude association between child maltreatment and child attachment styles, and few utilized a model examining the association among $\mathrm{MCAH}, \mathrm{MMH}$, parenting, and attachment simultaneously. The current results, which indicate that child maltreatment did not link $\mathrm{MCAH}$ and the child's attachment problems, may point to another pathway from MCAH to the child's attachment problems, involving poor parenting or genetic transmission relevant for oxytocin, as mentioned above. With regard to subtypes of child maltreatment in bivariate analyses, the mother's physical abuse before moving into the home had the strongest impact on attachment problems, followed by the mother's current psychological abuse, mother's psychological abuse before moving into the home, and father's severe physical abuse. Since the development of the attachment relationship usually occurs between the mother and infant during early childhood, the stronger impact of mother's physical and psychological abuse, particularly before moving into the home, is theoretically congruent.

This study had several limitations other than measurement bias. First, we did not assessed child attachment problem by staff members of the mother-child Home, which may provide more objective assessment if mother-child dyad and staff members interact with each other for substantial duration. Hence, further research is necessary to determine the validity and reliability of the scales used in this study, and it is recommended to replicate this study with assessment of child attachment problem by staff members of mother- 
Mizuki et al. Paediatrics and Health 2015,

child home. Second, the results of the study are difficult to generalize, even in mother-child homes, because of sampling bias inherent in a convenient sample of population for the study. Further research using the general population must be conducted to confirm the intergenerational continuity of child maltreatment. Third, we did not assess sexual abuse, which might not be rare in this population.

Despite the limitations, the finding that $\mathrm{MMH}$ and $\mathrm{MCAH}$, but not parental maltreatment, were independently associated with attachment problems in children has some welfare and clinical implications. It may be more effective to address and treat parents' mental health issues, especially dissociation, than to treat the presenting issues per se, when mothers visit mental health professionals to discuss the problems of their children, such as behavioral or mental problems. In cases of mothers suffering from dissociation, a decline in dissociative symptoms will enhance their understanding of parenting training and may lead to increasing consistency in parenting practice. Also, treating childhood abuse victimization for mothers appears to be a crucial intervention affecting the attachment problems of their children. In addition to psycho-education on attachment and parenting training, some attachment-based programs (e.g., Child-Parent Psychotherapy) incorporate interventions directly addressing parents' childhood experiences, particularly in relation to their parents [42]. Attachment programs addressing childhood abuse victimization of parents, as well as psychotherapy for trauma survivors, might be necessary when clinicians treat parents with such experiences. As for the welfare system, the assessment of mother's childhood abuse history and mental health conditions at the time of moving into the mother-child home may allow the support staff to better understand the mother's functioning, and they can use this to develop an assistance plan more suitable and effective for the mother and her family.

\section{Conclusion}

$\mathrm{MCAH}$ and $\mathrm{MMH}$ were independently significantly associated with attachment problems in children. Non significant results with child maltreatment indicated that child maltreatment mediated the association between MCAH or $\mathrm{MMH}$ and the child's attachment problems. Among the three subtypes of $\mathrm{MMH}$, only dissociative symptoms were found to significantly predict the child's attachment problems, independent of MCAH and child maltreatment. In order to unfold the complex mechanisms of intergenerational continuity of maltreatment, further research is necessary, utilizing a nationally representative sample, prospective design, validated measures, and possibly an experimental observation. We investigated whether childhood abuse history influence on child's attachment problems, which is a risk factor for abusive parenting when the child become parent, using a cross-sectional study of mother-child homes in Japan. Maternal childhood abused history and maternal mental health were shown to be inde- pendently significantly associated with attachment problems in children, while child maltreatments were not found to be associated with attachment problem. Intervention for maternal childhood abused history is needed to remedy the intergenerational continuity of child abuse.

\section{Competing interests}

The authors declare that they have no competing interests.

Authors' contributions

\begin{tabular}{|l|c|c|c|}
\hline Authors' contributions & RM & TF & MO \\
\hline Research concept and design & -- & $\checkmark$ & $\checkmark$ \\
\hline Collection and/or assembly of data & -- & -- & $\checkmark$ \\
\hline Data analysis and interpretation & $\checkmark$ & $\checkmark$ & -- \\
\hline Writing the article & $\checkmark$ & $\checkmark$ & -- \\
\hline Critical revision of the article & -- & $\checkmark$ & -- \\
\hline Final approval of article & $\checkmark$ & $\checkmark$ & $\checkmark$ \\
\hline Statistical analysis & $\checkmark$ & $\checkmark$ & -- \\
\hline
\end{tabular}

Acknowledgement

This research was supported by Research on Self-Support of Victims of Domestic Violence and Its Support, in Research on Children and Families, Health and Labor Sciences Research Grants from the Ministry of Health, Labor and Welfare (PI: Tomoko Ishii).

\section{Publication history}

Editors: Mohamed Ibrahim Ali Omer, University of West Indies, Trinidad and Tobago.

Senior Editor: Victor C. Strasburger, UNM School of Medicine, USA. Received: 17-Mar-2015 Final Revised: 23-Apr-2015

Accepted: 05-May-2015 Published: 20-May-2015

\section{References}

1. Weinfield NS, Sroufe LA, Egeland B and Carlson E. Individual differences in infant-caregiver attachment: Conceptual and empirical aspects of security. In: Handbook of Attachment. Edited by Cassidy J, Shaver P. New York: Guilford Press. 2008; 78-101. I Article

2. Kim J and Cicchetti D. A longitudinal study of child maltreatment, mother-child relationship quality and maladjustment: the role of selfesteem and social competence. J Abnorm Child Psychol. 2004; 32:34154. | Article | PubMed

3. Smeekens S, Riksen-Walraven JM and van Bakel HJ. Multiple determinants of externalizing behavior in 5-year-olds: a longitudinal model. J Abnorm Child Psychol. 2007; 35:347-61. | Article I PubMed Abstract | PubMed Full Text

4. Sousa C, HerrenkohI TI, Moylan CA, Tajima EA, Klika JB, Herrenkohl RC and Russo MJ. Longitudinal study on the effects of child abuse and children's exposure to domestic violence, parent-child attachments, and antisocial behavior in adolescence. J Interpers Violence. 2011; 26:11136. | Article | PubMed Abstract | PubMed Full Text

5. Speltz ML, DeKlyen M and Greenberg MT. Attachment in boys with early onset conduct problems. Dev Psychopathol. 1999; 11:269-85. | Article | PubMed

6. van ljzendoorn $\mathrm{MH}$, Schuengel $\mathrm{C}$ and Bakermans-Kranenburg MJ. Disorganized attachment in early childhood: meta-analysis of precursors, concomitants, and sequelae. Dev Psychopathol. 1999; 11:225-249. | Article

7. Carlson V, Cicchetti D, Barnett D and Braunwald K. Disorganized/ disoriented attachment relationships in maltreated infants. Developmental Psychology. 1989; 25:525. | Article 
Mizuki et al. Paediatrics and Health 2015,

http://www.hoajonline.com/journals/pdf/2052-935X-3-3.pdf

doi: $10.7243 / 2052-935 X-3-3$

8. Easterbrooks MA, Biesecker $\mathrm{G}$ and Lyons-Ruth $\mathrm{K}$. Infancy predictors of emotional availability in middle childhood: the roles of attachment security and maternal depressive symptomatology. Attach Hum Dev. 2000; 2:170-87. | Article | PubMed

9. DeVito $\mathrm{C}$ and Hopkins J. Attachment, parenting, and marital dissatisfaction as predictors of disruptive behavior in preschoolers. Dev Psychopathol. 2001; 13:215-31. | Article | PubMed

10. Moss E, Cyr C and Dubois-Comtois K. Attachment at early school age and developmental risk: examining family contexts and behavior problems of controlling-caregiving, controlling-punitive, and behaviorally disorganized children. Dev Psychol. 2004; 40:519-32. | Article | PubMed

11. Madigan S, Bakermans-Kranenburg MJ, Van Ijzendoorn MH, Moran G, Pederson DR and Benoit D. Unresolved states of mind, anomalous parental behavior, and disorganized attachment: a review and metaanalysis of a transmission gap. Attach Hum Dev. 2006; 8:89-111. | Article I PubMed

12. Fujiwara T, Okuyama M and Izumi M. The cycle of violence: Childhood abuse history, domestic violence and child maltreatment among Japanese mothers. Psychologia. 2010; 53:211-224. | Article

13. Kovan NM, Chung AL and Sroufe LA. The intergenerational continuity of observed early parenting: a prospective, longitudinal study. Dev Psychol. 2009; 45:1205-13. | Article | PubMed

14. Widom CS. Does violence beget violence? A critical examination of the literature. Psychol Bull. 1989; 106:3-28. | Article | PubMed

15. Van ljzendoorn $\mathrm{MH}$. Intergenerational transmission of parenting: $\mathbf{A}$ review of studies in nonclinical populations* 1 . Developmental review. 1992; 12:76-99. | Pdf

16. McCartney K, Owen MT, Booth CL, Clarke-Stewart A and Vandell DL. Testing a maternal attachment model of behavior problems in early childhood. J Child Psychol Psychiatry. 2004; 45:765-78. | Article | PubMed

17. Murray L, Sinclair D, Cooper P, Ducournau P, Turner P and Stein A. The socioemotional development of 5-year-old children of postnatally depressed mothers. J Child Psychol Psychiatry. 1999; 40:1259-71. | Article I PubMed

18. Cicchetti D, Rogosch FA and Toth SL. Maternal depressive disorder and contextual risk: contributions to the development of attachment insecurity and behavior problems in toddlerhood. Dev Psychopathol. 1998; 10:283-300. | Article | PubMed

19. Martins $C$ and Gaffan EA. Effects of early maternal depression on patterns of infant-mother attachment: a meta-analytic investigation. $J$ Child Psychol Psychiatry. 2000; 41:737-46. | Article | PubMed

20. Howes $C$ and Spieker $S$. Attachment relationships in the context of multiple caregivers. In: Handbook of Attachment. Edited by Cassidy J, Shaver P. New York: Guilford Press. 2008; 317-332. I Article

21. Bogels $S$ and Phares V. Fathers' role in the etiology, prevention and treatment of child anxiety: a review and new model. Clin Psychol Rev. 2008; 28:539-58. | Article I PubMed

22. Grossmann K, Grossmann KE, Fremmer-Bombik E, Kindler H, ScheuererEnglisch $\mathrm{H}$ and Zimmermann $\mathrm{P}$. The uniqueness of the child-father attachment relationship: Fathers' sensitive and challenging play as a pivotal variable in a 16-year longitudinal study. Social Development. 2002; 11:301-337. | Article |

23. Bernstein DP, Fink L, Handelsman L, Foote J, Lovejoy M, Wenzel K, Sapareto $E$ and Ruggiero J. Initial reliability and validity of a new retrospective measure of child abuse and neglect. Am J Psychiatry. 1994; 151:1132-6. | Article | PubMed

24. Fujiwara T, Okuyama M, Izumi M and Osada Y. The impact of childhood abuse history and domestic violence on the mental health of women in Japan. Child Abuse Negl. 2010; 34:267-74. | Article | PubMed

25. Fujiwara T, Okuyama M and Izumi M. The cycle of violence: childhood abuse history, domestic violence and child maltreatment among Japanese mothers. Psychologia. 2010; 53:211-224. | Article

26. Fujiwara T, Okuyama $M$ and Izumi $M$. The impact of childhood abuse history, domestic violence and mental health symptoms on parenting behaviour among mothers in Japan. Child Care Health Dev. 2012; 38:530-7. | Article I PubMed
27. Fujiwara Fujiwara T, Okuyama M and Izumi M. Factors that contribute to the improvement in maternal parenting after separation from a violent husband or partner. J Interpers Violence. 2012; 27:380-95. | Article | PubMed

28. Fujiwara T and Okuyama M. Mediators of Intergenerational Continuity of Child Maltreatment among Japanese Mothers. International Journal of Social Science Studies. 2013; 1:181-189. | Article

29. Matsuura N, Fujiwara T, Okuyama M and Izumi M. Testing a cascade model of linkage between child abuse and negative mental health among battered women in Japan. Asian J Psychiatr. 2013; 6:99-105. Article I PubMed

30. American Psychiatric Association. Diagnostic and Statistical Manual of Mental Disorders, (DSM-IV). 1994

31. Fujiwara T, Okuyama M, Izumi M and Osada Y. The impact of childhood abuse history and domestic violence on the mental health of women in Japan. Child Abuse Negl. 2010; 34:267-74. | Article | PubMed

32. Center for Child Abuse Prevention. General household survey: Current status of mother's child maltreatment In. Tokyo: Report of grant aid for child care. Welfare and Medical Service. Fiscal Year 1998. 1999.

33. Izumi M and Okuyama M. Development of Checklist for Maltreated Young Children. Pscyhiatria et neurologia paediatrica Japonica. 2009; 49:121-130.

34. Bronfman E, Parsons E and Lyons-Ruth K. A typical Maternal Behavior Instrument for Assessment and Classification (AMBIANCE): Manual for coding disrupted affective communication. Version 2. 02139: 1993. In: Unpublished manuscript, Harvard Mdical School, Cambridge, MA. 1999

35. Main $\mathrm{M}$ and Solomon J. Procedures for identifying infants as disorganized/disoriented during the Ainsworth Strange Situation. In: Attachment in the preschool years: Theory, research, and intervention. Edited by Greenberg MT, Cicchetti D, Cummings EM, Chicago: University of Chicago Press. 1990; 1:121-160. | Article

36. Ainsworth MDS, Blehar MC, Waters $E$ and Wall S. Patterns of attachment: A psychological study of the strange situation. Hillsdale, NJ. 1978.

37. Lyons-Ruth $\mathrm{K}$ and Block $\mathrm{D}$. The disturbed caregiving system: Relations among childhood trauma, maternal caregiving, and infant affect and attachment. Infant Mental Health Journal. 1996; 17:257-275. | Article

38. Atkinson L, Paglia A, Coolbear J, Niccols A, Parker KC and Guger S. Attachment security: a meta-analysis of maternal mental health correlates. Clin Psychol Rev. 2000; 20:1019-40. | Article | PubMed

39. Lyons-Ruth K, Bronfman E and Parsons E. Atypical attachment in infancy and early childhood among children at developmental risk. IV. Maternal frightened, frightening, or atypical behavior and disorganized infant attachment patterns. Monogr Soc Res Child Dev. 1999; 64:67-96. PubMed

40. Abrams KY, Rifkin A and Hesse E. Examining the role of parental frightened/frightening subtypes in predicting disorganized attachment within a brief observational procedure. Dev Psychopathol. 2006; 18:34561. | Article | PubMed

41. Cyr C, Euser EM, Bakermans-Kranenburg MJ and Van ljzendoorn $\mathrm{MH}$. Attachment security and disorganization in maltreating and high-risk families: a series of meta-analyses. Dev Psychopathol. 2010; 22:87-108. | Article | PubMed

42. Berlin L, Zeanah C and Lieberman A: Prevention and intervention programs for supporting early attachment security. In: Handbook of attachment. Edited by Cassidy J, Shaver P. New York: Guilford Press. 2008; 745-761.

Citation:

Mizuki R, Fujiwara T and Okuyama M. Impact of maternal childhood abuse history on child's attachment problems. Paediatr Health. 2015; 3:3. http://dx.doi.org/10.7243/2052-935X-3-3 